\title{
Renoprotective effect of a dopamine D3 receptor antagonist in experimental type II diabetes
}

\author{
Marie-Luise P Gross ${ }^{1}$, Andreas Koch², Bernd Mühlbauer ${ }^{3}$, Marcin Adamczak², \\ Heike Ziebart ${ }^{1}$, Karla Drescher ${ }^{4}$, Gerhard Gross ${ }^{4}$, Irina Berger ${ }^{1}$, Kerstin U Amann ${ }^{5}$ \\ and Eberhard Ritz ${ }^{2}$

\begin{abstract}
${ }^{1}$ Department of Pathology, University of Heidelberg, Heidelberg, Germany; ${ }^{2}$ Department of Internal Medicine, University of Heidelberg, Heidelberg, Germany; ${ }^{3}$ Department of Clinical Pharmacology, Klinikum Bremen-Mitte, Bremen, Germany; ${ }^{4}$ ABBOTT GmbH \& Co. KG Ludwigshafen, Ludwigshafen, Germany; and ${ }^{5}$ Department of Pathology, University of Erlangen, Erlangen, Germany
\end{abstract}

\begin{abstract}
Diabetic nephropathy is the leading cause of end-stage renal disease. Dopamine receptors are involved in the regulation of renal hemodynamics and may play a role in diabetes-induced hyperfiltration. To test this hypothesis, we investigated the renal effect of a dopamine D3 receptor antagonist (D3-RA) in hypertensive type II diabetic SHR/N-cp rats. Lean and obese SHR/N-cp rats were randomly assigned to D3-RA, angiotensinconverting enzyme inhibitor (ACE-i), or D3-RA + ACE-i treatment or control conditions. Treated animals were given the D3-RA A-437203 (10 mg/kg/body weight (BW)/day) or the ACE-i trandolapril $(0.3 \mathrm{mg} / \mathrm{kg} \mathrm{BW/day)}$ or a combination of both. At 6 months following perfusion, fixed kidneys were analyzed by morphological and stereological methods. Indices of renal damage (glomerulosclerosis, glomerulosclerosis damage index (GSI), tubulointerstitial and vascular damage), glomerular geometry and functional variables such as urinary albumin excretion, glomerular filtration rate, blood pressure, blood chemistry and BW were determined. The GSI (score $0-4)$ was significantly higher $(P<0.05)$ in untreated diabetic animals $(1.62 \pm 0.3)$ compared to nondiabetic controls (0.4 \pm 0.2$)$ and the treatment groups (D3-RA: $0.31 \pm 0.12$; ACE-i: $0.29 \pm 0.1$; combination treatment: $0.12 \pm 0.01)$. Urinary albumin excretion $(\mathrm{mg} / 24 \mathrm{~h})$ was higher in untreated diabetic controls $(102 \pm 19)$ compared to nondiabetic controls $(31 \pm 12)$ and the treatment groups (D3-RA: $44 \pm 15$; ACE-i: $41 \pm 13$; combination treatment: $15 \pm 8$ ). Mean glomerular volume was higher in untreated diabetic animals compared to nondiabetic controls and to the treatment groups. Desmin expression, a marker of podocyte damage, was elevated in untreated diabetic controls and diminished in all treatment groups. These data suggest that in a model of type II diabetes, the dopamine D3-RA had a beneficial effect on renal morphology and albuminuria, which was comparable in magnitude to that of ACE-i treatment.

Laboratory Investigation (2006) 86, 262-274. doi:10.1038/labinvest.3700383; published online 9 January 2006
\end{abstract}

Keywords: type II diabetes; dopamine receptor antagonist; glomerular cells; capillarization; progression; dopamine $D_{3}$ receptor

In recent years, the efficacy of pharmacological blockade of the renin-angiotensin system in diabetic nephropathy has been documented in experimental ${ }^{1}$ and clinical studies. ${ }^{2}$

Although this intervention is effective, it fails to abrogate progression of renal disease consistently and completely. There is a dire need for additional

Correspondence: Dr M-LP Gross, MD, Department of Pathology, University of Heidelberg, Im Neuenheimer Feld 220/221, Heidelberg 69120, Germany.

E-mail: Marie-Luise_Gross@med.uni-heidelberg.de

Received 23 August 2005; revised 16 November 2005; accepted 17

November 2005; published online 9 January 2006 or alternative interventions. Several innovative strategies have been proposed including blockade of the aldosterone receptor or pharmacological interference with the effects of cytokines and chemokines. We reasoned that one further promising intervention might be blockade of the renal effects of dopamine.

It is well known that dopamine, a central and peripheral neurotransmitter, is synthesized in non-neuronal tissues as well including renal tissue. It could potentially play a role in maintaining sodium balance by direct actions in the kidney and indirect actions mediated via catecholamines or the renin system. In the rat, juxtaglomerular cells are 
innervated by dopaminergic nerves and express the $\mathrm{D} 1_{\mathrm{A}}$ and D3 receptor subtypes. ${ }^{3-5}$ Activation of the D1 receptor was reported to increase renin release. ${ }^{3}$

It has been shown in several species that dopamine increases the glomerular filtration rate. More recently, selective D2-type antagonists were demonstrated to reverse glomerular hyperfiltration induced by amino acids ${ }^{6,7}$ or experimental diabetic hyperglycemia. ${ }^{8}$ In addition, activation of the D3 receptor in rats caused diuresis, natriuresis and increased glomerular filtration. ${ }^{9}$

In the present study, we used the SHR/N-cp rat as a hypertensive model of type II diabetes, which develops severe glomerular lesions ${ }^{1}$ to investigate a potential renoprotective action of a novel D3 receptor antagonist (D3-RA) compared to that of an angiotensin-converting enzyme inhibitor (ACE-i) as the gold standard.

\section{Materials and methods}

\section{Animals (Table 1)}

The SHR/N-cp rat is a novel model of type II diabetes. The animals develop marked renal lesions. ${ }^{10}$ This strain was generated by mating obese Koletzky rats and hypertensive SHR rats. The resultant progeny are either lean or obese. The diabetic SHR/N-cp inherits obesity as an autosomal recessive trait. As corpulent rats do not reproduce, the rats are bred by mating of heterozygous animals. Mating yields three genotype, but only two phenotypes, that is, the homozygous (cp/cp) corpulent as well as the heterozygous $(\mathrm{cp} /+)$ and homozygous $(+/+)$ lean rats, in a ratio of 1:2:1. The development of obesity is linked to reduced metabolic expenditure of energy. ${ }^{10-12}$

For the present study, 6-months-old male SHR/ $\mathrm{N}$-cp obese rats and their age-matched lean controls were obtained from Vasarr (New York, USA) and were housed at standard light cycle (light 0800-2000 hours daily), $40-70 \%$ relative humidity and maintained at $22 \pm 1^{\circ} \mathrm{C}$ in standard box cages. All animals were allowed free access to Standard Purina chow $\left(\mathrm{Na}^{+}\right.$content: $0.25 \%$; no. 5012; Purina Mills, St Louis, MO, USA) and water throughout the studies.

\section{Experimental Protocol}

The animals were randomly allotted to the following eight experimental groups:

1. SHR/N-cp lean untreated control $(n=9)$.

2. SHR/N-cp lean + dopamine receptor blocker (D3RA) A-437203 (10 mg/kg BW, $n=8)$.

3. SHR/N-cp lean + ACE-i trandolapril $(0.3 \mathrm{mg} / \mathrm{kg}$ BW, $n=13)$.

4. SHR/N-cp lean + ACE-i- + D3-RA $(n=7)$.

5. SHR/N-cp obese untreated control $(n=7)$.

6. SHR/N-cp obese + D3-RA $(n=9)$.

7. SHR/N-cp obese + ACE-i $(n=12)$.

8. SHR/N-cp obese + D3-RA + ACE-i $(n=7)$.

The drugs were administered in the drinking fluid at concentrations calculated to deliver the abovementioned doses. Doses of used drugs were selected based on data provided by ABBOTT from pilot studies in diabetic rats (data not shown). Daily food and water consumption were monitored and the drug doses adjusted. Body weight (BW), blood glucose and blood pressure (by tail plethysmography) were measured at regular intervals. After 6 months, animals were kept in metabolic cages for 1 day to collect $24 \mathrm{~h}$ urine. Urinary albumin excretion was measured using a rat-specific sandwich enzyme-linked immunoassay (ELISA) system as described in detail elsewhere. ${ }^{13}$ Blood samples were taken and the experiment was terminated after 6 months by retrograde perfusion via the abdominal aorta $^{1}$ under deep anesthesia. Cholesterol and leptin concentrations were measured by Limbach Laboratory (Heidelberg, Germany; courtesy Dr Roth).

Table 1 Animal data (at the end of the experiment)

\begin{tabular}{|c|c|c|c|c|c|c|c|}
\hline Animal group & $B W(g)$ & $\begin{array}{c}\text { Kidney } \\
\text { weight (g) }\end{array}$ & $\begin{array}{l}\text { Blood } \\
\text { glucose } \\
\text { (mg/dl) }\end{array}$ & $\begin{array}{l}\text { Systolic } \\
\text { blood } \\
\text { pressure } \\
(\mathrm{mmHg})\end{array}$ & $\begin{array}{l}\text { Albumin } \\
\text { excretion } \\
(\mathrm{mg} / 24 \mathrm{~h})\end{array}$ & $\begin{array}{l}\text { Glomerular } \\
\text { filtration } \\
\text { rate }(\mathrm{ml} / \\
\text { min) }\end{array}$ & $\begin{array}{c}\text { Sodium } \\
\text { excretion } \\
\text { (mmol/l } \\
\text { per day) }\end{array}$ \\
\hline Lean nondiabetic SHR/N-cp ( & $457 \pm 30^{*+\S}$ & $\$ 1.73 \pm 0.17$ & $95 \pm 11^{*+\S}$ & $131 \pm 21^{*+\S}$ & $31 \pm 12^{*}+$ & $1.01 \pm 0.05^{*}$ & $50 \pm 17 *$ \\
\hline Lean 1 & 453 & $1.65 \pm 0.14$ & $89 \pm 21^{*+\S}$ & $119 \pm 19^{*+\S}$ & $8.1 \pm 5^{*}+$ & $1.02 \pm 0.09^{*}$ & $79 \pm 14^{*}$ \\
\hline ndiabetic SHR/N-cp & $391 \pm 71^{*+\S}$ & $1.53 \pm 0.29$ & $89 \pm 14^{*+\S}$ & $85 \pm 21^{\star \bullet}$ & $9.9 \pm 3^{*+\S}$ & $1.2 \pm 0.05^{*}$ & $69 \pm 18^{*}$ \\
\hline Lean nondiabetic SHR/N-cp+D3-RA+ & $466 \pm 27^{*+\S}$ & $1.67 \pm 0.13$ & $90 \pm 5^{*+\S}$ & $83 \pm 19^{* \bullet}$ & $6 \pm 2^{*+\S}$ & $1.3 \pm 0.3^{*}$ & $78 \pm 10^{*}$ \\
\hline Obes & 639 & $1.68 \pm 0.13$ & 167 & $149 \pm$ & $102=$ & & 121 \\
\hline tic SHR/N-cp+D3 & $666 \pm 60$ & $1.76 \pm 0.26$ & $185 \pm 67$ & $87 \pm 22 *$ & $44 \pm 15^{* \S}$ & $0.9 \pm 0.3^{*}$ & $89 \pm 19 *$ \\
\hline Diabetic SHR/N-cp+ACE-i $(n=9)$ & $626 \pm 74$ & $1.91 \pm 0.21$ & $147 \pm 84$ & $86 \pm 23^{*}$ & $41 \pm 13^{* \S}$ & $1.0 \pm 0.4^{*}$ & $88 \pm 16^{*}$ \\
\hline Diabetic SHR/N-cp+D3-RA+ACE-i $(n=$ & $633 \pm 129$ & $1.69 \pm 0.33$ & $125 \pm 76$ & $81 \pm 13^{*}$ & $15 \pm 8^{*+\S}$ & $1.16 \pm 0.3^{*}$ & $79 \pm 33^{*}$ \\
\hline ANOVA & $P<0.05$ & $\overline{N S}$ & $P<0.05$ & $P<0.05$ & $P<0.05$ & $P<0.05$ & $P<0.05$ \\
\hline
\end{tabular}

NS $=$ not significant.

${ }^{*} P<0.05$ vs obese control; ${ }^{+} P<0.05$ vs obese+ACE; ${ }^{\circledR} P<0.05$ vs obese+combination; ${ }^{\bullet} P<0.05$ vs lean control. 


\section{Tissue Preparation}

One kidney was harvested after perfusion with Rheomacrodex ${ }^{\circledR}$ and ice-cold saline for immunohistological and in situ investigations. The other organs were removed after continuous perfusion with glutaraldehyde for morphometric investigations. ${ }^{1}$ The glutaraldehyde-perfused kidney was dissected in a plane perpendicular to the interpolar axis, yielding slices of $1 \mathrm{~mm}$ width. In all, 10 small pieces of this kidney were selected by area-weighted sampling for embedding in Epon-Araldite. Semi$(1 \mu \mathrm{m})$ and ultrathin sections $(0.08 \mu \mathrm{m})$ were prepared and stained with methylene blue/basic fuchsin or citrate/uranyl acetate, respectively. The remaining tissue slices were embedded in paraffin; $4 \mu \mathrm{m}$ sections were prepared and stained with hematoxylin/eosin and PAS. For immunohistological investigations, one-half of the NaCl-perfused kidney was fixed in $4 \%$ buffered formaldehyde, embedded in paraffin and cut into $2 \mu \mathrm{m}$ thick sections. For in situ hybridization, the other half of the kidney was snap-frozen in liquid nitrogencooled isopentane.

\section{Morphological Investigations}

Indices of renal damage (glomerulosclerosis, tubulointerstitial and vascular damage)

The degree of sclerosis within the glomerular tuft as an index of progression (glomerulosclerosis damage index, GSI) was determined on PAS-stained paraffin sections adopting the semiquantitative scoring system proposed by El Nahas et al. ${ }^{14}$ Using light microscopy at a magnification of $\times 400$, the glomerular score of each animal was derived as the mean of 100 glomeruli. The severity of glomerulosclerosis was expressed on an arbitrary scale from 0 to 4 as described elsewhere. ${ }^{14,15}$

Tubulointerstitial damage index (TBI) and vascular damage index (VDI) were assessed on PASstained paraffin sections at a magnification of $\times 100$ using a similar scoring systems with scores $0-4 .^{16}$

\section{Glomerular geometry}

Area $\left(A_{\mathrm{A}}\right)$ and volume density $\left(V_{\mathrm{V}}\right)$ of the renal cortex and medulla as well as the number of intact glomeruli per area $\left(N_{\mathrm{A}}\right)$ were measured using a Zeiss eyepiece (Integrationsplatte II; Zeiss Co., Oberkochen, Germany) and the point counting method $\left(P_{\mathrm{P}}=A_{\mathrm{A}}=V_{\mathrm{V}}\right)$ at a magnification of $\times 400$, described in detail. ${ }^{17,18}$
Analysis of glomerular capillarization and cellularity on semithin sections
On five semithin sections per animal, glomerular capillarization and cellularity were analyzed using the point counting method and a 100-point eyepiece (Integrationsplatte II; Zeiss Co.) at a magnification of $\times 1000$ (oil immersion) as described previously. ${ }^{19}$

Briefly, the length density $\left(L_{v}\right)$ of glomerular capillaries was determined according to the standard stereological formula, $L_{\mathrm{v}}=2 Q_{\mathrm{A}}$ (with $Q_{\mathrm{A}}$ being the number of capillary transects per area of the capillary tuft). Total length of glomerular capillaries per one kidney $\left(L_{\text {total }}\right)$ was then derived from $L_{\mathrm{v}}$ and the total glomerular volume $\left(V_{\text {glom }}\right)$ with $V_{\text {glom }}=$ $V_{\text {vglom }} \times V_{\text {cortex }}$. Glomerular cellularity (podocytes, mesangial cell and endothelial cells) was assessed by stereological techniques in at least 30 glomeruli per animal from cell density per volume $\left(N C_{\mathrm{v}}\right)$ and volume density of the cell type $\left(V C_{\mathrm{v}}\right)$ according to the equation: $N c_{\mathrm{v}}=k / \beta \times N c_{\mathrm{A}}^{1.5} / V C_{\mathrm{v}}^{0.5}$, with $\beta$ for podocytes $=1.5$ and for mesangial and endothelial cell $=1.4$ and $k=1 .^{20}$ The respective cell volume was calculated with $V_{\mathrm{c}}=V C_{\mathrm{v}} \times V_{\text {glom }}$.

\section{Immunohistochemical Investigations}

Paraffin sections were reacted with antibodies using the avidin-biotin method:13,21 PCNA (proliferating cell nuclear antigen; $\alpha$-PCNA monoclonal mouse; Immunotech, Marseille, France; 1:150), TGF- $\beta 1$ (anti-TGF- $\beta 1$, rabbit polyclonal IgG; Santa Cruz Biotechnology, Santa Cruz, CA, USA; 1:300), fibronectin ( $\alpha$-fibronectin polyclonal rabbit; SigmaAldrich Chemie GmbH, Steinheim, Germany; 1:10), collagen IV (polyclonal rabbit; Biotrend, Cologne, Germany), nephrin (pan to nephrin; Flaunders, NJ, USA; 1:100) and desmin ( $\alpha$-desmin monoclonal mouse; DAKO, Hamburg, Germany; 1:400). Cryostat sections $(5 \mu \mathrm{m})$ were prepared and were reacted with antibodies using the avidin-biotin method: PDGF-AB (platelet-derived growth factor; $\alpha$-PDGF$\mathrm{AB}$ polyclonal goat; Upstate Biotechnology Inc., Waltham, USA; 1:50), collagen I (polyclonal rabbit; Chemicon, Tenecula, CA, USA; 1:2000) and endothelin ( $\alpha$-ET-1 polyclonal rabbit; Biotrend, Cologne, Germany; 1:20). PCNA immunohistochemistry was examined using light microscopy at a magnification of $\times 400$. In 50 glomeruli per kidney, the number of PCNA-positive cells per glomerulus as well as per glomerular and per tubulointerstitial area were counted.

The immunohistological stains were analyzed by two investigators masked to the allocation of the animals to treatment groups; scoring was performed as described in detail earlier. ${ }^{13}$

\section{Semiquantitative RT-PCR for Renal ET-1 and TGF- $\beta$ mRNÄ Expression}

The methods used have been described in detail elsewhere. ${ }^{18,19}$ Briefly, total RNA $(1 \mu \mathrm{g})$ was dissolved in $20 \mu \mathrm{l}$ of a reaction mixture containing 4 mM dATP, dCTP, dTTP and dGTP; 10 U RNAsin (Life Technologies BLR, Grand island, NY, USA); 100 pmol random hexamers (Boehringer Mannheim GmbH, Mannheim, Germany); PCR buffer (final concentrations: $1.6 \mathrm{mM}\left(\mathrm{NH}_{4}\right)_{2} \mathrm{SO}_{4}, 2.0 \mathrm{mM}$ Tris- 
$\mathrm{HCl}$ (pH 8.4), $1.5 \mathrm{mM} \mathrm{MgCl}_{2}$ ); and $100 \mathrm{U}$ Superscript reverse transcriptase (Life Technologies BLR). After incubation at $42^{\circ} \mathrm{C}$ for $45 \mathrm{~min}$, the enzyme was denatured for $5 \mathrm{~min}$ at $94^{\circ} \mathrm{C}$. Semiquantification of ET- 1 and TGF- $\beta$ mRNA was carried out using deletion mutants of the ET- 1 and TGF- $\beta$ cDNA as internal standard. The amplifications of the mutants resulted in PCR products of $300 \mathrm{bp}$ for ET-1 and $302 \mathrm{bp}$ for the TGF- $\beta$. The mutant cDNAs were added to the PCR mixture after RT to complete with the endogenous ET- $10.4 \mathrm{pg}$ (respectively TGF- $\beta$ $0.05 \mathrm{pg}$ ) of the plasmid was added to the PCR mixture per sample. The PCR products were separated in a $3 \%$ metaphorgel and scanned as TIF data. The quotient of measured endogenous sample and equivalent mutant was calculated by ScionImage-program (National Institute of Health, MD, USA).

\section{In Situ Hybridization for Renal TGF- $\beta$ mRNA and Collagen IV Expression}

Non radioactive in situ hybridization using TGF- $\beta$ sense and antisense probes was performed in five animals per group as described briefly: cryostat sections $(10 \mu \mathrm{m})$ were fixed with $3 \%$ paraformaldehyde/phosphate-buffered saline $\left(5 \mathrm{~min}, 4^{\circ} \mathrm{C}, \mathrm{pH}\right.$ 7.0). Subsequently, the sections were dehydrated, air-dried and stored at $-20^{\circ} \mathrm{C}$.

\section{Probe preparation and labelling}

A $340 \mathrm{bp}$ cDNA fragment of the TGF- $\beta$ cDNA was obtained from a PCR product using rat TGF- $\beta$ specific primers after RT of rat kidney total RNA. ${ }^{20}$ The segment encoding the TGF- $\beta$ gene was inserted into the pGEM-T vector system (Promega Biotech., Madison, WI, USA). For preparation of the antisense RNA probe, the plasmid was linearized with SpeI and transcribed using T7 bacteriophage RNA polymerase. Linearization of the plasmid with NcoI and transcription with SP6 RNA polymerase generated the sense RNA probe. Digoxigenin-labelled RNA probes were synthesized using a DIG RNA labelling mix (Roche, Mannheim, Germany). The sections were hybridized with $4 \mathrm{ng}$ of labelled probe in buffer in a moist chamber. Hybridization of the probe with native mRNA was allowed for $18 \mathrm{~h}$ at $50^{\circ} \mathrm{C}$. Afterwards, several posthybridization steps were performed. After posthybridization washes, the sections were equilibrated in buffer I. Nonspecific background staining was blocked by incubation for $1 \mathrm{~h}$ with $0.5 \%$ blocking reagent/buffer I (Roche, Mannheim, Germany). The hybridization products were visualized by ELISA using alkaline phosphatase-conjugated sheep anti-digoxigenin-Fab fragments (750 U/ml; Roche Mannheim, Germany). Following incubation at $4^{\circ} \mathrm{C}$ overnight, unbound conjugate was removed by two washes in buffer I followed by equilibration of the sections in buffer II. Nitroblue tetrazolium and 5-bromo-4-chloro-3-indo- lylphosphate served as chromogens. Negative controls included hybridization with the sense RNA probe, incubation without probe for detection of unspecific binding of the primary antibody and omission of both probe and primary antibody. Staining intensity was analyzed using the previously described semiquantitative scoring system (scores 0-4). ${ }^{20}$

Collagen IV sense and antisense probes were generously prevented by Professor J Floege and T Ostendorf (Aachen, Germany). ${ }^{22}$

\section{Statistics}

Data are given as mean \pm s.d. After testing for normal distribution, the Kruskal-Wallis test or one-way ANOVA were chosen for analysis of variance, followed by Duncan's multiple-range test to test for differences between groups. The results were considered significant when the probability of error $(P)$ was less than 0.05 .

\section{Results}

\section{Animal Data at the End of the Experiment (Tables 1 and 2)}

Nondiabetic control rats (lean) weighed significantly less than untreated diabetic animals (obese). Treatment with ACE-i or D3-RA had no influence on BW. Blood glucose was significantly higher in obese diabetic rats compared to both lean controls and treated animals. Systolic blood pressure was significantly higher in untreated obese animals compared to lean controls and all treatment groups. D3-RA treatment lowered blood pressure significantly in obese, but not in lean animals. Urinary albumin excretion was significantly lower in nondiabetic lean compared to obese diabetic rats. ACE-i and D3-RA reduced albuminuria in diabetic rats to a similar extent. The combination of both interventions in diabetic rats resulted in a significant additive beneficial effect.

In untreated diabetic rats, the glomerular filtration rate was significantly decreased; in contrast, sodium excretion rate was increased compared to nondiabetic controls. Both parameters were normalized in treated groups. Plasma leptin levels were significantly higher in diabetic animals compared to lean animals and were significantly lowered by all interventions. Triglycerides and cholesterol were significantly elevated in diabetic animals compared to lean controls and were lowered by ACE-i and combination treatment only.

\section{Morphological Investigations}

Indices of renal damage (Table 3, Figure 1)

Diabetes was associated with a significantly increased GSI in untreated rats (Table 3, Figure 1). 
Table 2 Blood chemistry (at the end of the experiment)

\begin{tabular}{|c|c|c|c|c|c|}
\hline Animal group & $H b A 1 c(\%)$ & Leptin $(n g / m l)$ & $\begin{array}{l}\text { Triglycerides } \\
\text { (mg/dl) }\end{array}$ & $\begin{array}{c}\text { Cholesterol } \\
\text { (mg/dl) }\end{array}$ & $L D L(\mathrm{mg} / \mathrm{dl})$ \\
\hline Lean nondiabetic SHR/N-cp $(n=9)$ & $5.56 \pm 0.75$ & $3.16 \pm 1.45^{*+\S}$ & $65.6 \pm 25.7^{*+\S}$ & $88.4 \pm 14.7^{*}$ & $22.1 \pm 7.4$ \\
\hline Lean nondiabetic SHR/N-cp+D3-RA $(n=8)$ & $5.12 \pm 0.21$ & $1.43 \pm 0.92^{*+\S}$ & $36.3 \pm 9.0^{*+\S}$ & $81.3 \pm 10.3^{*}$ & $22.1 \pm 3.5$ \\
\hline Lean nondiabetic SHR/N-cp+ACE-i $(n=13)$ & $4.72 \pm 0.21$ & $2.15 \pm 1.42^{*+\S}$ & $35.8 \pm 7.5^{*+\S}$ & $79.3 \pm 21.6^{*}$ & $12.4 \pm 4.5^{*}$ \\
\hline Lean nondiabetic SHR/N-cp+D3-RA+ACE-i $(n=7)$ & $5.29 \pm 0.37$ & $1.55 \pm 1.13^{*+\S}$ & $38.1 \pm 14.7^{*+\S}$ & $71.9 \pm 7.7^{*}$ & $16.3 \pm 4.3^{*}$ \\
\hline Obese diabetic SHR/N-cp $(n=7)$ & $5.27 \pm 0.56$ & $68.6 \pm 22.84$ & $513 \pm 75.2^{+\S}$ & $205 \pm 42.0$ & $31.8 \pm 5.9^{+}$ \\
\hline Obese diabetic SHR/N-cp+D3-RA $(n=7)$ & $6.04 \pm 0.92$ & $19.6 \pm 9.29^{*}$ & $520 \pm 47.8^{+\S}$ & $192 \pm 61.0$ & $36.2 \pm 36.8^{+}$ \\
\hline Obese diabetic SHR/N-cp+ACE-i $(n=9)$ & $5.12 \pm 0.32$ & $25.2 \pm 5.3^{*}$ & $276 \pm 45.6^{*}$ & $111 \pm 34.3^{*}$ & $9.3 \pm 3.4^{*}$ \\
\hline Obese diabetic SHR/N-cp+D3-RA+ACE-i $(n=12)$ & $5.98 \pm 0.89$ & $26.7 \pm 19 *$ & $266 \pm 24.9^{*}$ & $132 \pm 34.6^{*}$ & $10.3 \pm 8.4^{*}$ \\
\hline ANOVA & $\overline{N S}$ & $P<0.05$ & $P<0.05$ & $P<0.05$ & $P<0.05$ \\
\hline
\end{tabular}

$\mathrm{NS}=$ not significant.

${ }^{*} P<0.05$ vs obese control; ${ }^{+} P<0.05$ vs obese+ACE; ${ }^{\circledR} P<0.05$ vs obese+combination.

Table 3 Indices of renal damage and glomerular geometry

\begin{tabular}{|c|c|c|c|c|c|}
\hline Animal group & $\begin{array}{c}\text { GSI (score } \\
0-4 \text { ) }\end{array}$ & $\begin{array}{c}\text { TBI (score } \\
0-4 \text { ) }\end{array}$ & $\begin{array}{c}\text { VDI (score } \\
0-4)\end{array}$ & $\begin{array}{l}\text { Total number } \\
\text { of glomeruli } \\
\text { per one kidney }\end{array}$ & $\begin{array}{c}\text { Mean } \\
\text { glomerular } \\
\text { volume } \\
\left(\times 10^{6} \mu \mathrm{m}^{3}\right)\end{array}$ \\
\hline Lean nondiabetic SHR/N-cp $(n=9)$ & $0.4 \pm 0.2^{\star \S}$ & $1.3 \pm 0.3^{*}$ & $0.59 \pm 0.2^{*}$ & $33446 \pm 4678^{+\S}$ & $4.67 \pm 0.17^{*+\S}$ \\
\hline Lean nondiabetic SHR/N-cp+D3-RA $(n=8)$ & $0.2 \pm 0.1^{*}$ & $0.89 \pm 0.3^{*}$ & $0.49 \pm 0.2^{*}$ & $44454 \pm 2234^{*} \bullet$ & $3.31 \pm 0.21^{*} \bullet$ \\
\hline Lean nondiabetic SHR/N-cp+ACE-i $(n=13)$ & $0.2 \pm 0.2^{*}$ & $0.37 \pm 0.1^{* \#}$ & $0.29 \pm 0.2^{*}$ & $44748 \pm 1842^{* \bullet}$ & $3.45 \pm 0.4 * \bullet$ \\
\hline Lean nondiabetic SHR/N-cp+D3-RA+ACE-i $(n=7)$ & $0.1 \pm 0.4^{*}$ & $0.45 \pm 0.1^{\text {*\# }}$ & $0.31 \pm 0.1^{*}$ & $50254 \pm 5503 * \bullet$ & $3.21 \pm 0.21^{*} \bullet$ \\
\hline Obese diabetic SHR/N-cp $(n=7)$ & $1.62 \pm 0.3^{+\S}$ & $2.98 \pm 0.4^{\S}$ & $1.68 \pm 0.28^{+}$ & $32236 \pm 8881^{+\S}$ & $6.1 \pm 0.31^{+\S}$ \\
\hline Obese diabetic SHR/N-cp+D3-RA $(n=7)$ & $0.31 \pm 0.12 *$ & $1.4 \pm 0.4^{* \S}$ & $0.41 \pm 0.2^{*}$ & $52622 \pm 2194 *$ & $3.54 \pm 0.23^{*}$ \\
\hline Obese diabetic SHR/N-cp+ACE-i $(n=9)$ & $0.29 \pm 0.1^{*}$ & $0.89 \pm 0.1^{*}$ & $0.31 \pm 0.1^{*}$ & $51581 \pm 5714^{*}$ & $3.51 \pm 0.21 *$ \\
\hline Obese diabetic SHR/N-cp+D3-RA+ACE-i $(n=12)$ & $0.12 \pm 0.1^{*}$ & $0.6 \pm 0.3^{*}$ & $0.23 \pm 0.08^{*}$ & $54676 \pm 3631^{*}$ & $3.19 \pm 0.54 *$ \\
\hline ANOVA & $P<0.05$ & $P<0.05$ & $P<0.05$ & $P<0.05$ & $P<0.05$ \\
\hline
\end{tabular}

$\mathrm{GSI}=$ glomerulosclerosis index; TBI = tubulointerstitial damage index; VDI = vascular damage index.

${ }^{*} P<0.05$ vs obese control; ${ }^{+} P<0.05$ vs obese+ACE; ${ }^{\circledR} P<0.05$ vs obese+combination; ${ }^{\bullet} P<0.05$ vs lean control; ${ }^{*} P<0.05$ vs lean nondiabetic control.

In lean and obese rats, all pharmacological interventions reduced the GSI significantly and comparably. The TBI was higher in diabetic rats compared to nondiabetic animals. In treated animals, all interventions lowered tubulointerstitial lesions, but ACE-i and the combination treatment were much more effective than D3-RA. The VDI was higher in diabetic compared to nondiabetic rats and all interventions.

The number of glomeruli per kidney was lower in untreated lean and obese animals as compared to the treatment groups. All three pharmacological interventions resulted in a significantly higher number of glomeruli per kidney both in the lean and the diabetic SHR/N-cp. Mean glomerular volume was higher in untreated diabetic compared to nondiabetic animals and compared to the three intervention arms in lean and diabetic SHR/N-cp.

The length density is an acknowledged indicator of capillary obliteration and was lower in untreated diabetic compared to nondiabetic rats and all treatment groups.
In untreated diabetic compared to nondiabetic rats, the mean number of podocytes per glomerulus was lower and mean podocyte volume higher. In diabetic rats, all interventions prevented loss and hypertrophy of podocytes.

In diabetic rats, the endothelial cell number, the mesangial cell number and the mesangial matrix volume per glomerulus were higher compared to nondiabetic lean animals and all intervention groups.

\section{Immunohistochemical investigations (Table 4, Figures 2 and 3)}

PCNA: Untreated diabetic animals had more PCNApositive glomerular cells (mostly podocytes) per glomerular profile than nondiabetic lean controls. In lean animals, treatment had no effect on the number of PCNA + cells. ACE-i and combination treatment lowered the number of glomerular PCNA + cells. The D3-RA was less effective in this respect (see Table 4).

The number of PCNA-positive tubulointerstitial cells per view field was higher in untreated diabetic 

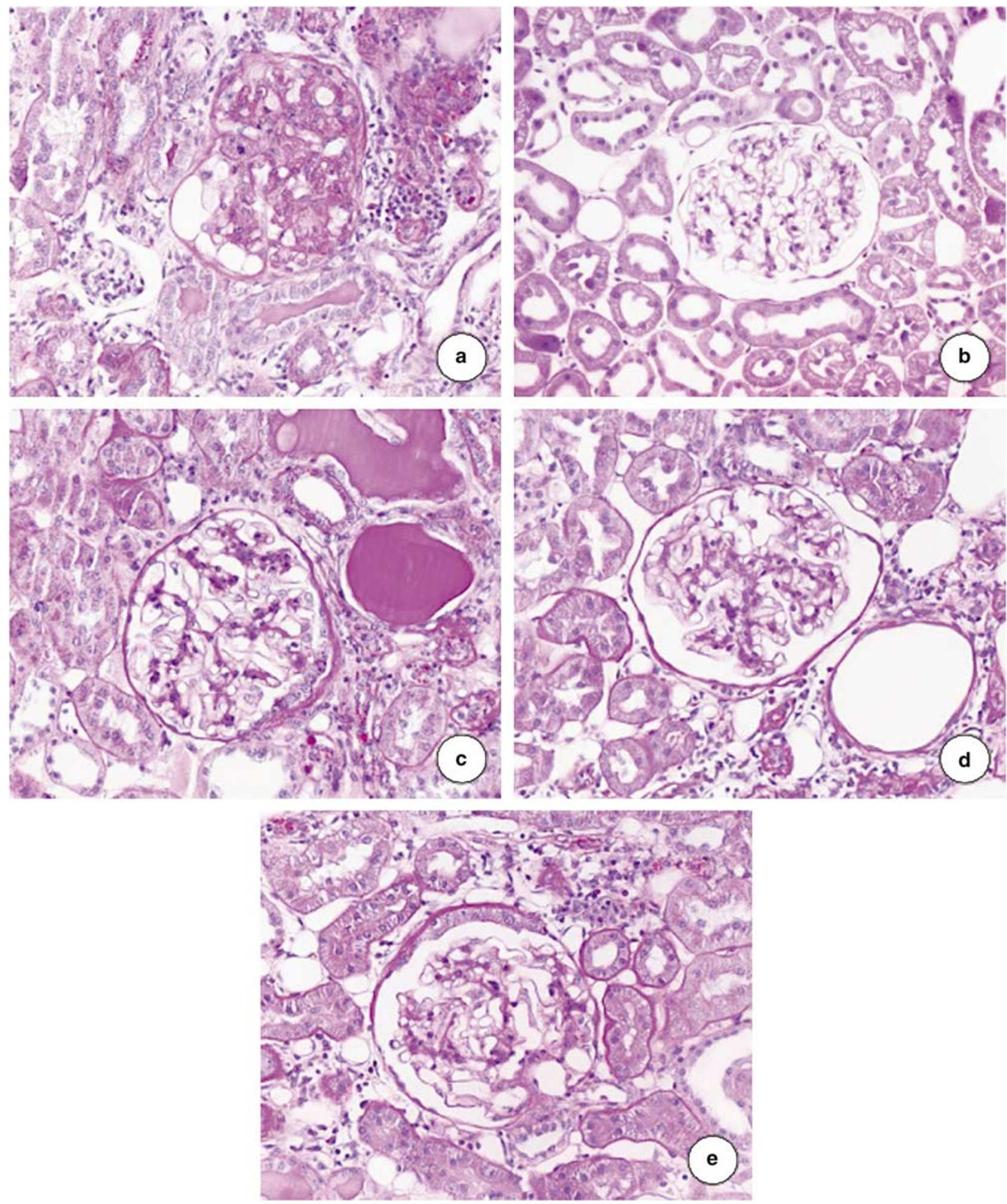

Figure 1 Representative sections of the kidney (PAS stain, magnification $\times 200$ ). (a) Untreated diabetic SHR/N-cp rat. Note marked sclerosis and attachment of the capillary tuft to the Bowman's capsule. The tubules are dilated, the epithelial cells are atrophic and the lumen is filled with eosinophilic material. Note patchy interstitial fibrosis with scanty round cell infiltrates. (b) Untreated lean nondiabetic control animal with regular glomerulus and normal tubulointerstitial tissue. (c) Diabetic SHR/N-cp treated with D3-RA. The glomerular structure is almost normal, but some tubulointerstitial changes are still visible. (d) Diabetic SHR/N-cp treated with ACE-i. Only minor mesangial matrix expansion in glomeruli and some inflammatory infiltrates are seen in the tubulointerstitium. (e) Diabetic SHR/N-cp treated with the combination ACE-i plus D3-RA. Glomeruli and tubulointerstitium are virtually normal. 
Table 4 Glomerular cells, capillary convolute and matrix volume

\begin{tabular}{|c|c|c|c|c|c|c|}
\hline Animal group & $\begin{array}{l}\text { Number of } \\
\text { podocytes }\end{array}$ & $\begin{array}{l}\text { Volume of } \\
\text { podocytes }\end{array}$ & $\begin{array}{c}\text { Mesangial cell } \\
\text { number }\end{array}$ & $\begin{array}{c}\text { Number of } \\
\text { endothelial } \\
\text { cells }\end{array}$ & $\begin{array}{l}L V \text { (length } \\
\text { density) } \\
\mathrm{mm} / \mathrm{mm}^{3}\end{array}$ & $\begin{array}{l}\text { Matrix } \\
\text { volume }\end{array}$ \\
\hline Lean nondiabetic SHR/N-cp $(n=9)$ & $264 \pm 55^{*}$ & $395 \pm 76^{*}$ & $258 \pm 50^{*}$ & $368 \pm 31^{*+\S}$ & $6248 \pm 1032 *$ & $2.32 \pm 1.6^{*}$ \\
\hline Lean nondiabetic SHR/N-cp+D3-RA $(n=8)$ & $233 \pm 59 *$ & $345 \pm 45^{*}$ & $213 \pm 48^{*}$ & $386 \pm 23 * \bullet$ & $8949 \pm 1299 *$ & $2.82 \pm 0.11^{*}$ \\
\hline Lean nondiabetic SHR/N-cp+ACE-i $(n=13)$ & $250 \pm 34^{*}$ & $309 \pm 34^{*}$ & $222 \pm 37^{* \#}$ & $399 \pm 40^{*} \bullet$ & $6874 \pm 832^{*}$ & $1.9 \pm 0.3^{*}$ \\
\hline Lean nondiabetic SHR/N-cp+D3-RA+ACE-i $(n=7)$ & $249 \pm 53^{*}$ & $342 \pm 32 *$ & $234 \pm 14^{* \#}$ & $389 \pm 21 * \bullet$ & $6400 \pm 456^{*}$ & $1.89 \pm 0.5^{*}$ \\
\hline Obese diabetic SHR/N-cp $(n=7)$ & $144 \pm 58^{+\S \varepsilon}$ & $641 \pm 56$ & $589 \pm 234^{\S}$ & $230 \pm 40^{+\S}$ & $4890 \pm 950$ & $8.39 \pm 2$ \\
\hline Obese diabetic SHR/N-cp+D3-RA $(n=7)$ & $357 \pm 12 *$ & $496 \pm 144$ & $299 \pm 76^{\star \S}$ & $317 \pm 32 *$ & $6907 \pm 115^{*}$ & $3.5 \pm 0.55^{*}$ \\
\hline Obese diabetic SHR/N-cp+ACE-i $(n=9)$ & $360 \pm 37^{*}$ & $444 \pm 48^{*}$ & $255 \pm 47^{*}$ & $332 \pm 68^{*}$ & $7298 \pm 299 *$ & $2.5 \pm 0.4^{*}$ \\
\hline Obese diabetic SHR/N-cp+D3-RA+ACE-i $(n=12)$ & $357 \pm 45^{*}$ & $440 \pm 81^{*}$ & $208 \pm 31 *$ & $319 \pm 54^{*}$ & $7339 \pm 845^{*}$ & $2.6 \pm 0.5^{*}$ \\
\hline ANOVA & $P<0.05$ & $P<0.05$ & $P<0.05$ & $P<0.05$ & $P<0.05$ & $P<0.05$ \\
\hline
\end{tabular}

${ }^{*} P<0.05$ vs obese control; ${ }^{+} P<0.05$ vs obese+ACE; ${ }^{\circledR} P<0.05$ vs obese+combination; $\bullet P<0.05$ vs lean control; ${ }^{*} P<0.05$ vs lean nondiabetic control; ${ }^{\star} P<0.05$ vs obese+D3-RA.

compared to nondiabetic lean rats. The number was lower in the ACE-i group and also combination treatment led to lower numbers of PCNA + glomerular cells in obese and lean rats. Again, the D3-RA was less effective in this respect (Table 5).

ET-1: ET-1 protein expression was higher in podocytes and mesangial cells of untreated diabetic rats compared to nondiabetic lean controls. In nondiabetic rats, the pharmacological interventions showed no significant effect, but in diabetic rats, all three treatments lowered the expression of ET-1 significantly. Tubulointerstitial staining with ET-1 was significantly more pronounced in diabetic compared to nondiabetic rats. In diabetic rats, the expression of ET-1 on the protein level was lower in the ACE-i and combination treatment groups only (see Figure 2).

Fibronectin: Fibronectin staining (score 0-4) was higher in glomeruli and tubulointerstitium of untreated diabetic (glomerular: 2.74 \pm 0.18 ; tubulointerstitial: $2.95 \pm 0.16)$ compared to nondiabetic lean rats (glomerular: 1.18 \pm 0.15 ; tubulointerstitial: $2.15 \pm 0.12$ ). None of the interventions showed a significant influence on glomerular and tubulointerstitial expression of fibronectin in lean rats. In diabetic rats, all pharmacological treatments lowered glomerular and tubulointerstitial expression of fibronectin (ACE-i-glomerular: $2.02 \pm 0.08$, tubulointerstitial: $1.93 \pm 0.07$; D3-RAglomerular: $2.29 \pm 0.12$, tubulointerstitial: $2.49 \pm$ 0.15 ; combination-glomerular: $2.18 \pm 0.09$, tubulointerstitial: $2.12 \pm 0.19$ ).

PDGF: Glomerular expression of PDGF-AB on the protein level showed no significant difference between the study groups. Tubulointerstitial expression of PDGF-AB was significantly $(P<0.05)$ higher in diabetic rats $(0.89 \pm 0.11)$ compared to lean nondiabetic animals $(0.32 \pm 0.12)$. Interventions had no influence in non-diabetic lean rats, but tubulointerstitial PDGF-AB expression was lower in diabetic rats after treatment with ACE-i $(0.31 \pm 0.09)$ and combination $(0.29 \pm 0.04)$, but not with D3-RA $(0.67 \pm 0.14)$.

$T G F-\beta 1$ : Glomerular and tubulointerstitial expression of TGF- $\beta 1$ was higher in diabetic compared to nondiabetic lean rats. In lean rats, the treatments had no significant effect. In diabetic rats, all intervention groups had significantly lower glomerular and tubulointerstitial expression $(P<0.05$; see Figure 4).

Desmin: Expression was virtually absent in podocytes of nondiabetic lean rats $(0.2 \pm 0.05)$ and was higher in podocytes of untreated diabetic rats $(1.5 \pm 0.4)$, indicating early podocyte damage. Desmin expression of podocytes was lower after treatment with ACE-i $(0.4 \pm 0.2)$, D3-RA $(0.5 \pm 0.3)$ and combination treatment $(0.4 \pm 0.2)$.

Nephrin: Expression was visible in podocytes of nondiabetic lean rats $(0.94 \pm 0.4)$ and was lower in obese rats $(0.41 \pm 0.2)$. Nephrin expression was higher in dopamine $(1.13 \pm 0.4)$, ACE-i $(1.21 \pm 0.2)$ and combination treated animals $(1.45 \pm 0.3)$.

Collagen I: Glomerular expression of collagen I was increased in diabetic obese rats $(2.4 \pm 0.12)$ compared to lean nondiabetic rats $(1.27 \pm 0.3)$. There was no significantly effect of treatment in nondiabetic lean rats, but in diabetic animals, all three pharmacological interventions lowered collagen I expression to a similar extent (ACE-i: $1.3 \pm 0.1$; D3RA: $1.43 \pm 0.4$; combination: $1.5 \pm 0.4$ ). Tubulointerstitial staining was also increased in obese rats $(2.28 \pm 0.47)$ compared to nondiabetic lean animals $(1.77 \pm 0.6)$. In lean animals, only ACE-i and combination treatment lowered expression (ACE-i: $1.19 \pm 0.1$; combination: $1.26 \pm 0.4$ ), but not D3-RA $(1.71 \pm 0.4)$. In obese animals, all interventions led to comparably lower tubulointerstitial expression for collagen I (ACE-i: $1.26 \pm 0.15$; D3-RA: $1.22 \pm 0.4$; combination: $1.21 \pm 0.5)$.

Collagen IV (see Figure 3): Expression of glomerular collagen IV was significantly higher in diabetic animals compared to lean controls. There was no effect of treatment in nondiabetic lean rats. In 

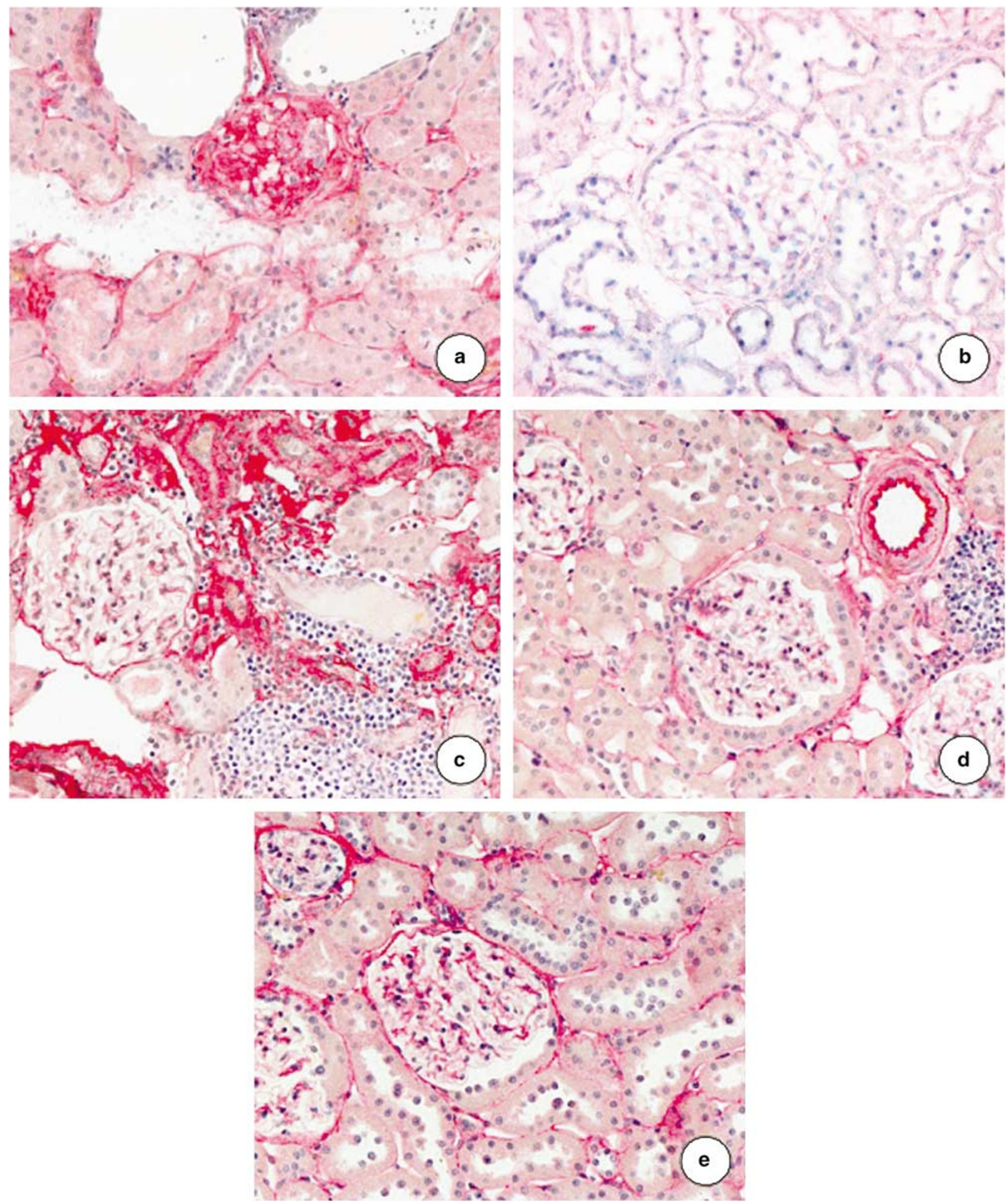

Figure 2 Effect of ACE-i and D3-RA on glomerular and tubulointerstitial endothelin-1 protein expression (immunohistochemistry, magnification $\times 300$ ). (a) Diabetic SHR/N-cp untreated. Note marked glomerular expression of endothelin-1. (b) Nondiabetic lean animal with no expression of endothelin-1. (c) Diabetic SHR/N-cp treated with D3-RA. Note low glomerular expression of endothelin-1, but relatively high tubulointerstitial expression. (d) Diabetic SHR/N/-cp treated with ACE-i. Note scanty glomerular endothelin-1 expression. (e) Diabetic SHR/N-cp animal treated with a combination of ACE-i and D3-RA. Note virtually absent glomerular and tubulointerstitial expression of ET-1. 
contrast, in diabetic animals, all interventions lowered collagen IV staining to a similar extent. Tubulointerstitial collagen IV expression was significantly higher in diabetic animals compared to
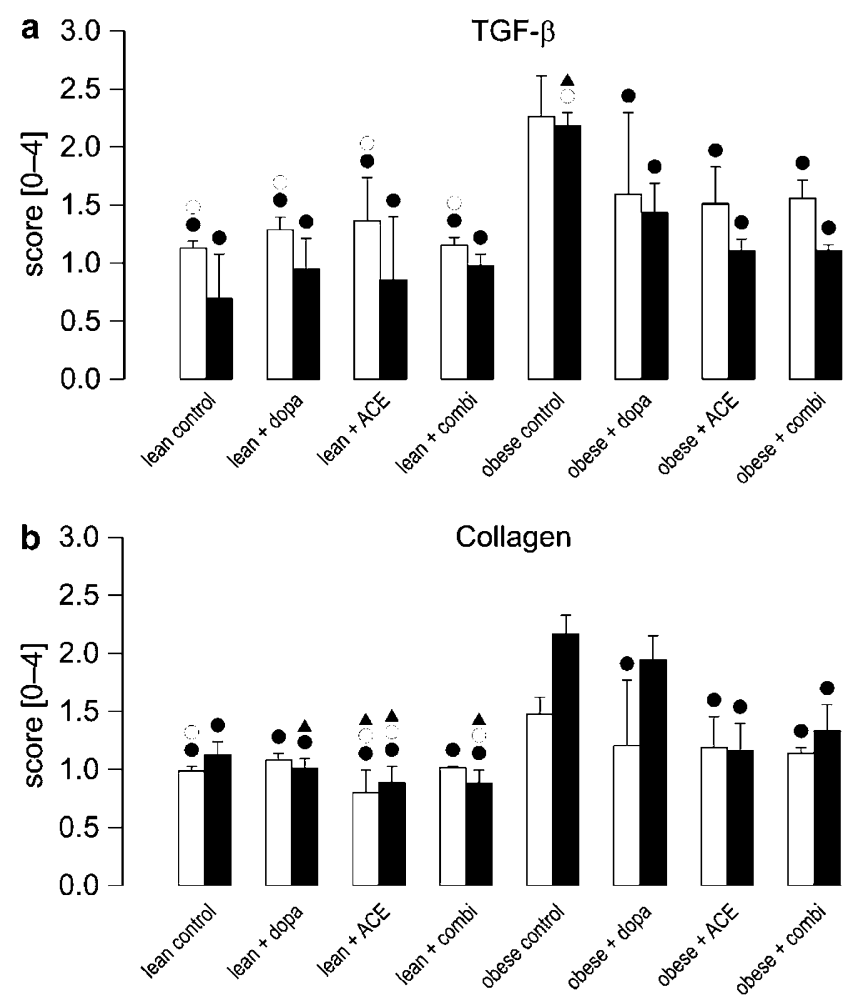

Figure 3 (a and b) Effect of ACE-i and D3-RA on glomerular and tubulointerstitial expression of TGF- $\beta$ (a) and collagen IV (b) in the diabetic and nondiabetic SHR/N-cp. $\square$, Glomerular expression; $\mathbf{\square}$, tubulointerstitial expression; $\bullet, P<0.05$ vs diabetic obese control; $\bigcirc, P<0.05$ vs obese + ACE-i; $\mathbf{\Lambda}, \quad P<0.05$ vs obese + combination. Glomerular and tubulointerstitial expression of TGF- $\beta 1$ (a) was higher in untreated diabetic compared to nondiabetic lean rats. In diabetic rats, all intervention groups had significantly lower glomerular and tubulointerstitial expression $(P<0.05)$. Expression of glomerular collagen IV (b) was significantly higher in diabetic animals compared to lean controls. Tubulointerstitial collagen IV expression was significantly higher in diabetic animals compared to lean rats. In diabetic rats, ACE-i and combination treatment, but not treatment with D3-RA lowered collagen IV expression significantly. lean rats. Again, there was no significant effect of treatment in nondiabetic lean animals. In diabetic rats, ACE-i and combination treatment, but not treatment with D3-RA lowered collagen IV expression significantly.

\section{RT-PCR for TGF- $\beta$ mRNA and ET-1 mRNA}

TGF- $\beta 1$ mRNA expression was increased in untreated diabetic rats $(83.8 \pm 23.7)$ compared to nondiabetic untreated rats $(39.7 \pm 17.8)$. In nondiabetic animals, there was no significant effect of treatment. In diabetic rats, TGF- $\beta 1$ mRNA expression was lower in animals treated with ACE-i $(35.9 \pm 22)$, in animals treated with D3-RA $(32.2 \pm 14.8)$ and combination treatment $(33.8 \pm 18.7)$.

ET-1 mRNA was increased in obese untreated animals $(116 \pm 37.1)$ compared to nondiabetic lean controls (53.4 \pm 18$)$. In nondiabetic animals, there was no significant effect of treatment. In obese diabetic rats, all three pharmacological interventions reduced ET-1 expression, but ACE-i and combination treatment were significantly $(P<0.05)$ more effective than therapy with the D3-RA alone (ACE-i: $50.6 \pm 13.4$; D3-RA: $88.5 \pm 20.1$; combination: $54.3 \pm 23.5)$.

In situ hybridization for TGF- $\beta$ mRNA and collagen IV mRNA

The expression of TGF- $\beta$ mRNA was higher in podocytes and mesangial cells of untreated diabetic rats compared to nondiabetic controls (score: $0.62 \pm 0.03$ vs $0.07 \pm 0.02$ ) or diabetic rats treated with ACE-i (score: $0.21 \pm 0.08$ ), D3-RA (score: $0.2 \pm 0.11$ ) or combination treatment (score: $0.18 \pm 0.1$ ). In the tubulointerstitial space expression of collagen IV, mRNA was stronger in untreated diabetic than in nondiabetic control rats (score: $0.97 \pm 0.44$ vs $0.124 \pm 0.14$ ) and in diabetic rats treated with ACE- $\bar{i}$ or the combination or ACEi + D3-RA (ACE-i: $0.14 \pm 0.02$; combination: $0.26 \pm 0.16)$. Treatment with $\mathrm{D} 3-\mathrm{RA}$ alone had no significant effect on expression of TGF- $\beta$ mRNA in the tubulointerstitial space: $0.61 \pm 0.2$.

Expression of collagen IV mRNA was higher in podocytes and mesangial cells of untreated diabetic

Table 5 Number of PCNA-positive glomerular and tubulointerstitial cells

\begin{tabular}{lcc}
\hline Animal group & PCNA-positive cells/glom. profile & PCNA-positive cells/tubuloint. area \\
\hline Lean nondiabetic SHR/N-cp $(n=9)$ & $7.5 \pm 4.0^{*}$ & $2.75 \pm 1.5^{*}$ \\
Lean nondiabetic SHR/N-cp+D3-RA $(n=8)$ & $9.75 \pm 4.8^{*}$ & $2.25 \pm 1.7^{*}$ \\
Lean nondiabetic SHR/N-cp+ACE-i $(n=13)$ & $8.4 \pm 5.7^{*}$ & $0.7 \pm 0.3^{*}$ \\
Lean nondiabetic SHR/N-cp+D3-RA+ACE-i $(n=7)$ & $7.4 \pm 3.3^{*}$ & $0.7 \pm 0.3^{*}$ \\
Obese diabetic SHR/N-cp $(n=7)$ & $59.8 \pm 8.0^{+\S}$ & $42.3 \pm 14.7^{+\S}$ \\
Obese diabetic SHR/N-cp+D3-RA $(n=7)$ & $25.5 \pm 3^{*+\S}$ & $31 \pm 16.6^{\S}$ \\
Obese diabetic SHR/N-cp+ACE-i $(n=9)$ & $7.1 \pm 2.7^{*}$ & $23.4 \pm 9.3^{*}$ \\
Obese diabetic SHR/N-cp+D3-RA+ACE-i $(n=12)$ & $5.6 \pm 2.2^{*}$ & $15.6 \pm 5.2^{*}$ \\
ANOVA & $P<0.05$ & $P<0.05$
\end{tabular}

${ }^{*} P<0.05$ vs obese control; ${ }^{+} P<0.05$ vs obese+ACE; ${ }^{\circledR} P<0.05$ vs obese+combi; $\bullet P<0.05$ vs lean control. 

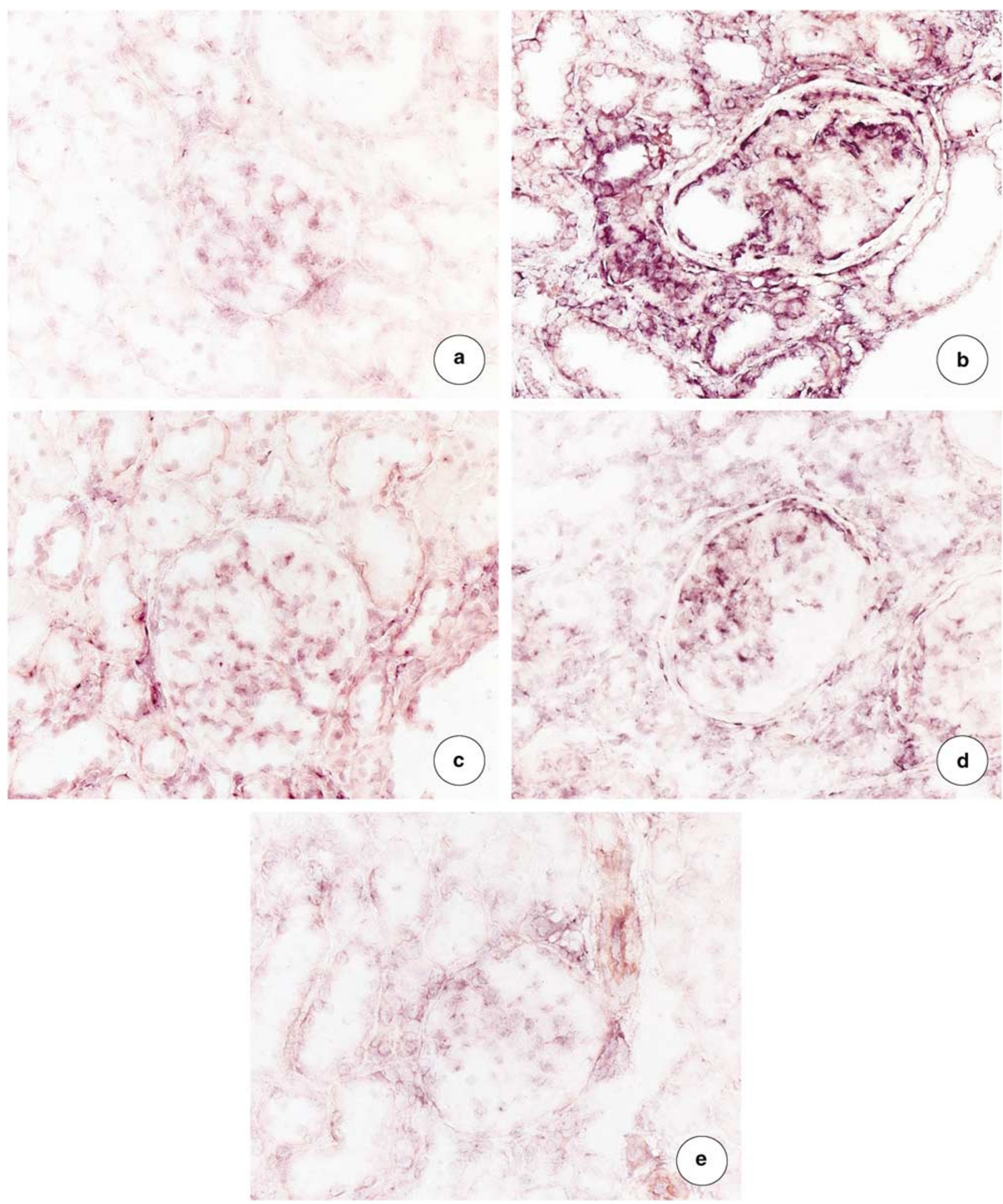

Figure 4 Effect of ACE-i and D3-RA on glomerular and tubulointerstitial collagen IV mRNA expression (nonradioactive in situ hybridization, magnification $\times 300$ ). (a) Nondiabetic control animal with virtually no collagen IV mRNA expression. (b) Untreated diabetic SHR/N-cp with increased collagen IV mRNA expression. (c) ACE-i-treated diabetic SHR/N-cp with only minor collagen IV mRNA expression. (d) D3-RA-treated diabetic SHR/N-cp with minor collagen IV mRNA expression. (e) Diabetic SHR/N-cp rat treated with a combination of ACE-i and D3-RA and normal collagen IV mRNA expression. 
rats than in nondiabetic controls (score: $0.83+0.08$ vs $0.06 \pm 0.08$; Figure 4 ). In diabetic rats treated with ACE-i (score: $0.04 \pm 0.08$ ), D3-RA (score: $0.17 \pm 0.11$ ) or their combination (score: $0.05 \pm 0.1$ ), it was significantly less as well. In the tubulointerstitial space expression of collagen IV, mRNA was stronger in untreated diabetic animals than in nondiabetic controls (score: $1.33 \pm 0.18$ vs $0.12 \pm 0.14$; Figure 4) or treated diabetic rats (ACE-i: $0.14 \pm 0.02$; D3-RA: $0.61 \pm 0.2$; combination: $0.26 \pm 0.16$ ) .

\section{Discussion}

The salient feature of the present study is the observation that the D3-RA proved to be a remarkably effective renoprotective agent in a type II diabetes animal model. Treatment with D3-RA had a beneficial effect on glomerular filtration rate, albuminuria, morphological indices of renal damage (GSI, TBI and VDI) as well as on the number of PCNA-positive cells in glomeruli and tubulointerstitium and finally on the expression of mediators of renal damage (ET-1, collagen IV, TGF- $\beta$ ). Treatment with the combination of an ACE-i with D3-RA had an even significantly greater effect than monotherapy.

Beneficial effects of a D3-RA are remarkable in view of the known actions mediated by the D3 dopaminergic receptor. Disruption of the D3 receptor increased renal renin production, and caused renal sodium retention as well as renin-dependent hypertension in one study. ${ }^{23}$ The ability of dopamine to stimulate renin secretion is enhanced by a low sodium diet and blunted by a high sodium diet. ${ }^{24}$ A defective renal dopaminergic system seems to be a major cause of renal malfunction in Dahl saltsensitive and spontaneously hypertensive rats: their kidneys produce less dopamine. The natriuretic and diuretic response to a sodium load is attenuated. ${ }^{25-27}$

In previous studies, D3-RA failed to change blood pressure values. In the present study, we found an antihypertensive effect of D3-RA, which was comparable in magnitude to the effect of an ACE-i. This effect may contribute to the renoprotective action. We believe, however, that the opposite is more probable, that is, that the effect of D3-RA on renal hemodynamics might have beneficially influenced systemic blood pressure.

The effect of the D3-RA on albuminuria was comparable in magnitude to that of monotherapy with an ACE-i, while the combination showed additive efficacy. This finding in diabetic animals cannot be solely explained by blood pressure effects, since in lean animals the D3-RA also reduced albuminuria to a similar extent, although no change in blood pressure was observed. Such an antiproteinuric effect is remarkable, since albuminuria induced by high altitude hypoxia is increased by dopamine. There is increasing interest in hypoxia as a mediator of progressive renal damage. ${ }^{28,29}$ Studies of Norman et $a l^{30}$ documented that hypoxia increases matrix synthesis and decreases matrix breakdown in the renal interstitium.

Diabetic patients have an impaired ability to excrete sodium. It has been hypothesized that defective renal tubular dopamine mobilization may be responsible. ${ }^{31} \mathrm{~A}$ defective renal dopamine system has been documented early in type I diabetic patients and in individuals with familial hypertension. ${ }^{32}$

Glomerular hypertension/hyperfiltration plays a major role in the development of diabetic nephropathy. ${ }^{33}$ A D3 agonist caused a dose-related increase of glomerular filtration rate by up to $20 \%{ }^{34}$ Conversely, D3-RAs decrease glomerular hyperfiltration in experimental diabetes in rats. ${ }^{35}$

The D3-RA had remarkable effects on the renal structure. The glomerular volume was significantly increased in the diabetic SHR/N-cp and decreased in all pharmacological intervention groups. Since perfusion pressure during fixation was rigorously controlled, it is unlikely that the difference in glomerular volume was an artifact. It is very interesting that the D3-RA prevented not only the decrease of glomerular number in untreated diabetic animals compared to diabetic animals treated with ACE-i alone or combined with the DR3-RA. The latter prevented loss and hypertrophy of podocytes as well. The hypothesis had been advanced that dopamine D3 receptors are important modulators of glomerular filtration and contribute to hyperfiltration in diabetes. ${ }^{35}$ Our results are in agreement with this concept. In the glomerulus, strong D3 receptor immunoreactivity was demonstrated in podocytes ${ }^{36}$ and less pronounced in mesangial cells. ${ }^{37}$ The latter is relevant to the in vitro observation that angiotensin II induces a shape change of mesangial cells, which is abrogated by dopamine. ${ }^{38}$ The expression of D3 receptors on podocytes and mesangial cells is also relevant with respect to our observation that D3-RA prevented podocyte loss and mesangial cell growth in diabetic animals.

In diabetic animals, monotherapy with the D3-RA reduced glomerulosclerosis and vascular damage and also prevented mesangial cell growth and endothelial cell loss as effectively as an ACE-i.

The TBI was also somewhat lowered by the D3RA; howeverm far less than with an ACE-i. These differences of the effect of a D3-RA were paralleled by the known differences in the expression of D3 receptors. They are found in glomerular cells and in proximal tubular epithelial cells, but not in cells of the tubulointerstitial space. Presumably under the stimulating influence of angiotensin II, cells in the tubulointertitium express TGF- $\beta$ and ET-1. This finding explains the expected effect of ACE-i on the expression of TGF- $\beta$ and ET- 1 confirmed in the present study by immunohistochemistry, RT-PCR and in situ hybridization. Combination treatment led to numerically lower values of these parameters, but this was not statistically significant. 
Podocyte damage was documented in our study by expression of desmin, which is known to be a sensitive marker of podocyte injury. ${ }^{39}$ All pharmacological interventions lowered podocyte damage. Podocytes possess receptors for a variety of hormones, including adrenergic beta (2) and dopamine $\mathrm{D}(1)$ receptors, stimulation of which increases cAMP, ${ }^{40}$ a potent regulator of actin assembly, cell morphology and matrix production. ${ }^{40}$ D3 receptors are expressed by podocytes as well, but not by mesangial cells as documented by O'Connell et $a 1^{36}$ using immunohistochemistry. This is one further argument to assume that the beneficial effect of the D3-RA on GSI and desmin staining is a direct action of the antagonist and not an indirect result of altered hemodynamics.

It has been suggested that filtration slit structure injury and, in particular, podocyte loss contribute to the progressive development of glomerulosclerosis and albuminuria in diabetic nephropathy. ${ }^{41}$ Nephrin is located in the slit diaphragm of the glomerular podocyte barrier. Interestingly, ACE-i and D3-RB increased the expression of nephrin to a similar extent. It remains undecided, however, whether increased expression of nephrin and decreased expression of desmin in treated diabetic rats results from lower blood pressure and less proteinuria or whether it reflects a primary action of the D3-RA.

The SHR/N-cp rat is a model of type II diabetes, with modest hyperglycemia, but marked obesity. There is increasing evidence that obesity is a potent risk factor for progression. ${ }^{4-44}$ In the present study, obese SHR/N-cp rats had significantly higher plasma leptin concentrations. Leptin is a potential progression promoter ${ }^{45}$ and enhances the effect of TGF- $\beta{ }^{46,47}$ The action of leptin in some cells is mediated by norepinephrine, a leptin-inducible neurotransmitter. Against this background, it is of interest that both ACE-i and D3-RA reduced leptin concentrations in the present study.

In conclusion, the present experiments show a beneficial action of D3-RA treatment on renal changes in experimental type II diabetes, characterized by a lower albumin excretion and less structural damage. These effects were comparable to those achieved by ACE-i treatment. Since ACE inhibitors fail to completely prevent progression in patients with diabetic nephropathy, it would be of interest to evaluate whether the combination of an ACE-i with a D3-RA has superior efficacy in humans as well.

\section{Acknowledgement}

M Adamczak has been supported by a Marie Curie Fellowship of the European Community programme: Improving the Human Research Potential and the Socio-economic knowledge base under Contract Number: HPMF-CT-2001-01501. The skilful technical assistance of Z Antoni, P Rieger and $S$ Söllner is gratefully acknowledged. We thank
Dr V Henschel, Department of Biostatistics, University of Heidelberg for statistical advice. Special thanks to $\mathrm{H}$ Derks and U Burkhardt for organizing photographs and the layout.

\section{References}

1 Gross ML, Ritz E, Schoof A, et al. Renal damage in the SHR/N-cp type 2 diabetes model: comparison of an angiotensin-converting enzyme inhibitor and endothelin receptor blocker. Lab Invest 2003;83: 1267-1277.

2 Thurman JM, Schrier RW. Comparative effects of angiotensin-converting enzyme inhibitors and angiotensin receptor blockers on blood pressure and the kidney. Am J Med 2003;114:588-598.

3 Yamaguchi I, Yao L, Sanada H, et al. Dopamine D1A receptors and renin release in rat juxtaglomerular cells. Hypertension 1997;29:962-968.

4 Sanada H, Yao L, Jose PA, et al. Dopamine D3 receptors in rat juxtaglomerular cells. Clin Exp Hypertens 11997;9:93-105.

5 Ferguson M, Bell C. Two patterns of dopa decarboxylase immunoreactivity in sympathetic axons supplying rat renal cortex. Ren Physiol Biochem 1991;14: 55-62.

6 Luippold G, Muhlbauer B. Dopamine D2 receptors mediate glomerular hyperfiltration due to amino acids. J Pharmacol Exp Ther 1998;286:1248-1252.

7 Luippold G, Schneider S, Stefanescu A, et al. Dopamine D2-like receptors and amino acid-induced glomerular hyperfiltration in humans. Br J Clin Pharmacol 2001;51:415-421.

8 Luippold G, Beilharz M, Muhlbauer B. Reduction of glomerular hyperfiltration by dopamine $\mathrm{D}(2)$-like receptor blockade in experimental diabetes mellitus. Nephrol Dial Transplant 2001;16:1350-1356.

9 Luippold G, Schneider S, Vallon V, et al. Postglomerular vasoconstriction induced by dopamine $\mathrm{D}(3)$ receptor activation in anesthetized rats. Am J Physiol Renal Physiol 2000;278:F570-F575.

10 Tulp OL, Weng M. Effect of genetic dilution on development of diabetes, impaired glucose tolerance and in vitro glucose oxidation in LA/N-cp $\times$ SHR/N-cp F1 hybrid rats. Comp Biochem Physiol Comp Physiol 1992;101:403-408.

11 Marette A, Tulp OL, Bukowiecki LJ. Mechanism linking insulin resistance to defective thermogenesis in brown adipose tissue of obese diabetic SHR/N-cp rats. Int J Obes Relat Metab Disord 1991;15:823-831.

12 Marette A, Deshaies Y, Collet AJ, et al. Major thermogenic defect associated with insulin resistance in brown adipose tissue of obese diabetic SHR/N-cp rats. Am J Physiol 1991;261:E204-E213.

13 Schwarz U, Amann K, Orth SR, et al. Effect of 1,25 $(\mathrm{OH}) 2$ vitamin D3 on glomerulosclerosis in subtotally nephrectomized rats. Kidney Int 1998;53:1696-1705.

14 el Nahas AM, Bassett AH, Cope GH, et al. Role of growth hormone in the development of experimental renal scarring. Kidney Int 1991;40:29-34.

15 Gandhi M, Olson JL, Meyer TW. Contribution of tubular injury to loss of remnant kidney function. Kidney Int 1998;54:1157-1165.

16 Veniant M, Heudes D, Clozel JP, et al. Calcium blockade versus ACE inhibition in clipped and 
unclipped kidneys of 2K-1C rats. Kidney Int 1994;46: 421-429.

17 Weibel ER. Measuring through the microscope: development and evolution of stereological methods. J Microsc 1989;155(Part 3):393-403.

18 Amann K, Koch A, Hofstetter J, et al. Glomerulosclerosis and progression: effect of subantihypertensive doses of alpha and beta blockers. Kidney Int 2001;60:1309-1323.

19 Amann K, Nichols C, Tornig J, et al. Effect of ramipril, nifedipine, and moxonidine on glomerular morphology and podocyte structure in experimental renal failure. Nephrol Dial Transplant 1996;11:1003-1011.

20 Gross ML, El-Shakmak A, Szabo A, et al. ACEinhibitors but not endothelin receptor blockers prevent podocyte loss in early diabetic nephropathy. Diabetologia 2003;46:856-868.

21 Wolf G, Wenzel U, Ziyadeh FN, et al. Angiotensin converting-enzyme inhibitor treatment reduces glomerular p16INK4 and p27Kip1 expression in diabetic BBdp rats. Diabetologia 1999;42:1425-1432.

22 Canaan-Kuhl S, Ostendorf T, Zander K, et al. C-type natriuretic peptide inhibits mesangial cell proliferation and matrix accumulation in vivo. Kidney Int 1998;53:1143-1151.

23 Asico LD, Ladines C, Fuchs S, et al. Disruption of the dopamine D3 receptor gene produces renin-dependent hypertension. J Clin Invest 1998;102:493-498.

24 Williams BC, Eglen A, Duncan FM, et al. The effect of sodium intake on the renin response to dopamine in superfused rat renal cortical cells. J Hypertens 1985; (Suppl 3):S267-S268.

25 DeFeo ML, Jadhav AL, Lokhandwala MF. Dietary sodium intake and urinary dopamine and sodium excretion during the course of blood pressure development in Dahl salt-sensitive and salt-resistant rats. Clin Exp Hypertens 1987;A9:2049-2060.

26 Racz K, Kuchel O, Buu NT. Abnormal adrenal catecholamine synthesis in salt-sensitive Dahl rats. Hypertension 1987;9:76-80.

27 Sakamoto T, Chen C, Lokhandwala MF. Lack of renal dopamine production during acute volume expansion in Dahl salt-sensitive rats. Clin Exp Hypertens 1994;16:197-206.

28 Fine LG, Bandyopadhay D, Norman JT. Is there a common mechanism for the progression of different types of renal diseases other than proteinuria? Towards the unifying theme of chronic hypoxia. Kidney Int Suppl 2000;75:S22-S26.

29 Hansen JM, Kanstrup IL, Richalet JP, et al. High altitude-induced albuminuria in normal man is enhanced by infusion of low-dose dopamine. Scand J Clin Lab Invest 1996;56:367-372.

30 Norman JT, Orphanides C, Garcia P, et al. Hypoxiainduced changes in extracellular matrix metabolism in renal cells. Exp Nephrol 1999;7:463-469.

31 Stenvinkel P, Saggar-Malik AK, Wahrenberg H, et al. Impaired intrarenal dopamine production following intravenous sodium chloride infusion in type 1 (insulin-dependent) diabetes mellitus. Diabetologia 1991;34:114-118.

32 Rudberg S, Lemne C, Persson B, et al. The dopaminuric response to high salt diet in insulin-dependent diabetes mellitus and in family history of hypertension. Pediatr Nephrol 1997;11:169-173.

33 Mogensen CE, Christensen CK. Predicting diabetic nephropathy in insulin-dependent patients. N Engl J Med 1984;311:89-93.

34 Muhlbauer B, Kuster E, Luippold G. Dopamine D(3) receptors in the rat kidney: role in physiology and pathophysiology. Acta Physiol Scand 2000;168: 219-223.

35 Luippold G, Beilharz M, Wehrmann M, et al. Effect of dopamine $\mathrm{D}(3)$ receptor blockade on renal function and glomerular size in diabetic rats. Naunyn Schmiedebergs Arch Pharmacol 2005;371:420-427.

36 O’Connell DP, Vaughan CJ, Aherne AM, et al. Expression of the dopamine D3 receptor protein in the rat kidney. Hypertension 1998;32:886-895.

37 Barili P, Ricci A, Baldoni E, et al. Pharmacological characterisation and autoradiographic localisation of a putative dopamine D3 receptor in the rat kidney. Eur J Pharmacol 1997;338:89-95.

38 Barnett R, Singhal PC, Scharschmidt LA, et al. Dopamine attenuates the contractile response to angiotensin II in isolated rat glomeruli and cultured mesangial cells. Circ Res 1986;59:529-533.

39 Phillips AO, Baboolal K, Riley S, et al. Association of prolonged hyperglycemia with glomerular hypertrophy and renal basement membrane thickening in the Goto Kakizaki model of non-insulin-dependent diabetes mellitus. Am J Kidney Dis 2001;37: $400-410$.

40 Endlich N, Endlich K. cAMP pathway in podocytes. Microsc Res Technol 2002;57:228-231.

41 Bonnet F, Cooper ME, Kawachi H, et al. Irbesartan normalises the deficiency in glomerular nephrin expression in a model of diabetes and hypertension. Diabetologia 2001;44:874-877.

42 Klahr S, Morrissey J. Progression of chronic renal disease. Am J Kidney Dis 2003;41:S3-S7.

43 Bonnet F, Deprele C, Sassolas A, et al. Excessive body weight as a new independent risk factor for clinical and pathological progression in primary IgA nephritis. Am J Kidney Dis 2001;37:720-727.

44 Kambham N, Markowitz GS, Valeri AM, et al. Obesityrelated glomerulopathy: an emerging epidemic. Kidney Int 2001;59:1498-1509.

45 Wolf G, Chen S, Han DC, et al. Leptin and renal disease. Am J Kidney Dis 2002;39:1-11.

46 Han DC, Isono M, Chen S, et al. Leptin stimulates type I collagen production in $\mathrm{db} / \mathrm{db}$ mesangial cells: glucose uptake and TGF-beta type II receptor expression. Kidney Int 2001;59:1315-1323.

47 Tang M, Potter JJ, Mezey E. Leptin enhances the effect of transforming growth factor beta in increasing type I collagen formation. Biochem Biophys Res Commun 2002;297:906-911. 